\title{
Synthesis and Experimental Validation of New PDI Inhibitors with Antiproliferative Activity
}

\author{
Mariateresa Badolato, Gabriele Carullo, Francesca Aiello, and Antonio Garofalo \\ Department of Pharmacy, Health and Nutritional Sciences, University of Calabria, Via Pietro Bucci, \\ 87036 Arcavacata di Rende, Italy \\ Correspondence should be addressed to Francesca Aiello; francesca.aiello@unical.it
}

Received 2 April 2017; Revised 3 May 2017; Accepted 9 May 2017; Published 15 June 2017

Academic Editor: Joaquin Campos

Copyright (C) 2017 Mariateresa Badolato et al. This is an open access article distributed under the Creative Commons Attribution License, which permits unrestricted use, distribution, and reproduction in any medium, provided the original work is properly cited.

\begin{abstract}
Protein disulfide isomerase (PDI) is a member of the thioredoxin superfamily of redox enzymes. PDI is a multifunctional protein that catalyzes disulfide bond formation, cleavage, and rearrangement in unfolded or misfolded proteins and functions as a chaperone in the endoplasmic reticulum. Besides acting as a protein folding catalyst, several evidences have suggested that PDI can bind small molecules containing, for example, a phenolic structure, which includes the estrogenic one. Increasing studies indicate that PDI is involved in both physiology and pathophysiology of cells and tissues and is involved in the survival and proliferation of different cancers. Propionic acid carbamoyl methyl amides (PACMAs) showed anticancer activity in human ovarian cancer, both in vitro and in vivo, by inhibiting PDI. The inhibition of PDI's activity may have a therapeutic role, in various diseases, including cancer. In the present study, we designed and synthesized a diversified small library of compounds with the aim of identifying a new class of PDI inhibitors. Most of synthesized compounds showed a good inhibitory potency against PDI and particularly 4-methyl substituted 2,6-di-tert-butylphenol derivatives (8-10) presented an antiproliferative activity in a wide panel of human cancer cell lines, including ovarian ones.
\end{abstract}

\section{Introduction}

Protein disulfide isomerase (PDI) belongs to the thioredoxin superfamily of oxidoreductases and is the founding member of the PDI family, consisting of 20 related mammalian proteins. All members of this family share the thioredoxinlike domain structure, characterized by the $\beta \alpha \beta \alpha \beta \alpha \beta \beta \alpha$ fold [1]. PDI (Figure 1) is a soluble $55-\mathrm{kDa}$ protein with four tandem thioredoxin-like domains, namely, $\mathbf{a}, \mathbf{b}, \mathbf{b}^{\prime}$, and $\mathbf{a}^{\prime}$. The homologous $\mathbf{a}$ and $\mathbf{a}^{\prime}$ domains contain the catalytically active site of PDI, which consists of a CGHC (Cys-Gly-HisCys) motif. The cysteines can exist either in an intramolecular disulfide (oxidized PDI) or in the dithiol form (reduced PDI) and interact with newly synthesized proteins, mediating thiol-disulfide exchanges. The $\mathbf{b}$ and $\mathbf{b}^{\prime}$ domains link the active site domains and assist in the binding of protein substrates. The $\mathbf{b}^{\prime}$ domain was identified as the chaperone domain, by NMR and X-ray crystallography. Between the $\mathbf{b}^{\prime}$ and the $\mathbf{a}^{\prime}$ domains there is a short $\mathbf{x}$-linker interdomain region, responsible for the U-shape structure of PDI. The acidic C-terminus of PDI is followed by an endoplasmic reticulum (ER) retrieval signal, KDEL [1-3]. A recent crystal structure of yeast PDI reveals that this protein has a high flexibility, essential for its enzymatic activity, in vitro and in vivo [4]. Several studies have suggested that PDI can function as an intracellular binding protein. In human breast cancer cells, it has been shown that PDI can modulate the intracellular level of $17 \beta$-estradiol $\left(\mathrm{E}_{2}\right)$, increase its hormonal activity, and reduce its metabolic availability [5]. Although the $\mathrm{E}_{2}$-binding site structure of human PDI is still not known, it is located to a hydrophobic pocket between the $\mathbf{b}$ and the $\mathbf{b}^{\prime}$ domains [6].

PDI is a multifunctional protein, acting as a folding enzyme by catalyzing the formation (oxidation), cleavage (reduction), and rearrangement (isomerization) of the disulfide bonds in unfolded or misfolded proteins [7]. It has also been proposed to function as a molecular chaperone in the refolding of denatured protein in vitro $[8,9]$. Depending on 


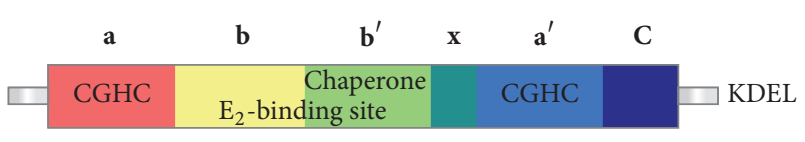

FIGURE 1: Domain structure of PDI.

its initial concentration, PDI exhibits both chaperone and antichaperone activities [10]. PDI is ubiquitously expressed but is primarily localized in the ER of eukaryotic cells, where it maintains an oxidant environment, contributing to ER homeostasis [11-14]. Despite the presence of the ER retention sequence, PDI has been localized in diverse subcellular places, such as cell surface, cytosol, mitochondria, and extracellular matrix [15]. The mechanism by which PDI gets away from the ER is still unclear. Originally, PDI was considered necessary to maintain healthy cells and tissues, while recent studies indicate that this protein is involved in both their physiology and pathophysiology. In particular, PDI has a protective effect in neurodegenerative conditions and cardiovascular diseases. PDI is also implicated in mediating the entry of pathogens during infectious diseases [3]. In many different cancer types, including brain, lymphoma, kidney, ovarian, prostate, lung, and male germ cell tumors, PDI is highly expressed and upregulated [16]. Although more than four decades of studies exist on PDI, its role in cancer progression is not well understood yet. Acting as an ER chaperone, PDI might play a role in the survival of metastatic breast cancers [17]. Suppression of apoptosis by PDI has been proposed as possible mechanism for tumor growth and metastasis. In fact, knockdown of PDI induces cytotoxicity in human breast cancer and activates apoptotic signaling in MCF-7 cells [18]. Cell surface PDI is also associated with cancer progression and migration of glioma cells [19]. Since PDI is involved in many important cell functions, among which is supporting the growth and invasion of various cancer types; in the past years PDI has received considerable attention as a potential drug target, especially for cancer therapy [16]. The modulation of PDI's activity with function-specific inhibitors may have a therapeutic role in various diseases including cancer. A wide range of drugs, including antibiotics, estrogen, polyphenols, and heterocyclic compounds, have been found to inhibit PDI [2023]. Propionic acid carbamoyl methyl amides (PACMAs) can inhibit irreversibly PDI, by forming a covalent bond (C-S) with the cysteines in the active site. In particular, PACMA 31 showed anticancer activity in human ovarian cancer, both in vitro and in vivo [24]. As an important considerable drug target, PDI has attracted our interest. With the aim of identifying new PDI inhibitors, considered an attracting approach for the treatment of cancer, we screened a small library of compounds using the insulin turbidimetry assay [16]. Lactone frame was identified as a potential inhibitor of PDI activity, so we modified and optimized the identified scaffold to improve upon its potency (Figure 2).

Based on the structure of known PDI modulators, bearing specific substituents in critical positions, we also designed and synthesized a new class of compounds, 4-methyl substituted 2,6-di-tert-butylphenol derivatives. We kept some
TABLE 1: Inhibition of PDI reductase activity (expressed in \%) by the synthesized compounds and $\mathrm{IC}_{50}$ values of the most potent ones.

\begin{tabular}{lcc}
\hline Compound & $\begin{array}{c}\text { PDI reductase activity } \\
\text { inhibition }(\%)\end{array}$ & $\mathrm{IC}_{50}(\mu \mathrm{M})$ \\
\hline PACMA 31 & 80.5 & $\mathbf{1 0 . 0} \pm \mathbf{0 . 1 0}$ \\
$\mathbf{1}$ & 57.2 & \\
$\mathbf{2}$ & 35.9 & \\
$\mathbf{3}$ & $\mathbf{8 0 . 7}$ & $>\mathbf{3 0}$ \\
$\mathbf{4}$ & $\mathbf{9 3 . 3}$ & $>\mathbf{3 0}$ \\
$\mathbf{5}$ & $\mathbf{8 7 . 6}$ & $>\mathbf{3 0}$ \\
$\mathbf{6}$ & 64.6 & \\
7 & 22.6 & \\
$\mathbf{8}$ & $\mathbf{9 8 . 5}$ & $\mathbf{1 . 5 1} \pm \mathbf{0 . 0 9}$ \\
$\mathbf{9}$ & $\mathbf{9 7 . 5}$ & $\mathbf{1 . 6 9} \pm \mathbf{0 . 2 2}$ \\
$\mathbf{1 0}$ & $\mathbf{8 2 . 3}$ & $\mathbf{4 . 1 7} \pm \mathbf{0 . 4 0}$ \\
\hline
\end{tabular}

Each value represents the average of three independent experiments \pm SD.

structural similarities with the known ligands, with the aim of enriching and diversifying our small library (Figure 3).

In this study, we investigated and reported the inhibitory effects of all synthesized compounds against the reductase activity of PDI. Compounds 3-5 and 8-10 highly inhibited the PDI reductase activity (see Table 1 ). In addition, the cytotoxicity of all synthesized compounds was also evaluated against different cancer cell lines, including ovarian tumor (see Table 2). Compounds 8-10 showed a good potency again. These results suggest that the new 4-methyl substituted 2,6di-tert-butylphenol derivatives are potential antiproliferative agents, targeting PDI.

\section{Material and Methods}

2.1. Chemistry. All reagents were purchased from SigmaAldrich and used without further purification. Solvents were dried and distilled according to conventional procedures. Reactions were carried out under nitrogen $\left(\mathrm{N}_{2}\right)$ atmosphere, monitored by thin layer chromatography (TLC) on silica gel plates (Merck 60F254, $0.2 \mathrm{~mm}$ ) and visualized by UV light at 254 and $366 \mathrm{~nm}$ of wavelength. Organic solutions were dried over anhydrous $\mathrm{NaSO}_{4}$ and evaporated on a rotary evaporator under reduced pressure. Final compounds were purified by flash chromatography columns, on silica gel (Merck, 60, 230-400 mesh, 0.040-0.063 mm). Melting points were obtained by a GallenKamp21374 apparatus and were uncorrected. ${ }^{1} \mathrm{H}-\mathrm{NMR}$ spectra were recorded on a Bruker $300 \mathrm{MHz}$ spectrometer. Chemical shift $(\delta)$ was reported in $\mathrm{ppm}$, using tetramethylsilane (TMS) as the internal reference standard. Multiplicities, coupling constants reported as a $J$ value in Hertz (Hz), and number of protons are indicated parenthetically. Mass spectra data were determined after electron impact ionization at $70 \mathrm{eV}$ with HP $5973 \mathrm{MS}$ spectrometer. Yields refer to purified products and are not optimized.

2.1.1. Synthetic Procedures. As known in literature [25], the indole and pyrrole lactones (1-5) were synthesized as 

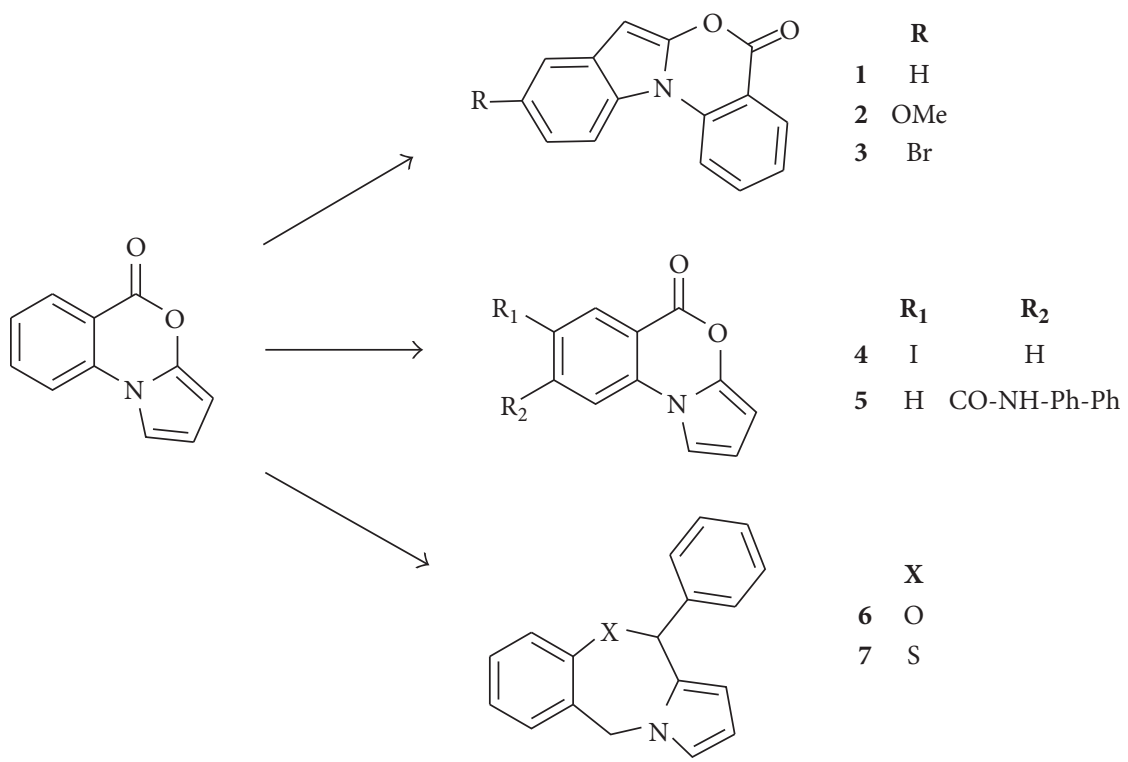

FIGURE 2: Chemical modifications made to the identified scaffold.

(1)

$\mathbf{E}_{2}$<smiles>C#CC(=O)N(c1ccc(OC)cc1OC)C(C(=O)NCC(=O)OCC)c1cccs1</smiles>

PACMA 31<smiles>CC(C)C</smiles><smiles>[R]C(c1cc(C(C)(C)C)c(O)c(C(C)(C)C)c1)c1cccs1</smiles><smiles>[R]CN1CCCCC1CN1CCOCC1</smiles>

FIGURE 3: Design of a new class of PDI inhibitors.

depicted in Scheme 1. The further formation of amide 5 was obtained following a classical synthetic method.

Scheme 2 represents the synthetic pathway for 11-phenyl$5 \mathrm{H}, 11 \mathrm{H}$-benzo[f]pyrrolo[2,1-c] [1,4] oxazepine (6). The starting (1-(2-fluorobenzyl)-1H-pyrrol-2-yl)(phenyl)methanol was synthesized following the procedure described by Garofalo et al. [26]. Finally, the cyclization of compound 6 was obtained, according to the reaction conditions described by Effland and Davis [27].
The synthesis of 11-phenyl-5H,11H-benzo[f]pyrrolo[2,1c] $[1,4]$ thiazepine (7) was realized following a similar procedure [26].

The 4-methyl substituted 2,6-di-tert-butylphenol derivatives (8-10) were synthesized by a catalyst-free reaction between thiophene-2-carbaldehyde, a cyclic amine, and 2,6di-tert-butylphenol (Scheme 3).

2.1.2. General Procedure for the Synthesis of 5H-Benzo[4, 5,1,3]oxazino[3,2-a]indol-5-one Derivatives (1-3) and 7-iodo$5 H$-benzo[d]pyrrolo[2,1-b][1,3]oxazin-5-one (4). The synthesis of the aforementioned compounds was obtained following the same procedure. Characterization data are in agreement with published data [25].

2.1.3. 5H-Benzo[4,5,1,3]oxazino[3,2-a]indol-5-one (1). Brown solid (49\% yield); mp: $123-124^{\circ} \mathrm{C} ;{ }^{1}$ H NMR: known compound [25].

2.1.4. 9-Methoxy-5H-benzo[4,5][1,3]oxazino[3,2-a]indol-5one (2). Amorphous yellow solid (32\% yield); ${ }^{1} \mathbf{H}$ NMR $\left(\mathrm{CDCl}_{3}\right) \boldsymbol{\delta}: 8.28(\mathrm{dd}, 1 \mathrm{H}, J=1.4,5.1 \mathrm{~Hz}) ; 8.09(\mathrm{~d}, 1 \mathrm{H}, J=$ $8.3 \mathrm{~Hz}) ; 7.91-7.78$ (m, 1H); 7.37-7.31 (m, 2H); 7.11 (t, 1H); 6.94 (dd, $1 \mathrm{H}, J=2.6,4.2 \mathrm{~Hz}) ; 6.16(\mathrm{~s}, 1 \mathrm{H}) ; 3.39$ (s, 3H); MS (EI. $70 \mathrm{eV}): m / z 266[\mathrm{M}+\mathrm{H}]^{+}$.

2.1.5. 9-Bromo-5H-benzo[4,5][1,3]oxazino[3,2-a]indol-5-one (3). Beige solid (54\% yield); mp: $162-163^{\circ} \mathrm{C} ;{ }^{1}$ HNMR: known compound [25].

2.1.6. 7-Iodo-5H-benzo[d]pyrrolo[2,1-b][1,3]oxazin-5-one (4). Yellow solid (28\% yield); mp: $128^{\circ} \mathrm{C} ;{ }^{1} \mathbf{H ~ N M R}\left(\mathbf{C D C l}_{3}\right) \boldsymbol{\delta}: 8.52$ $(\mathrm{s}, 1 \mathrm{H}) ; 8.03(\mathrm{dd}, 1 \mathrm{H}, J=2.1,8.6 \mathrm{~Hz}) ; 7.25(\mathrm{dd}, 1 \mathrm{H}, J=2.3$, $8.6 \mathrm{~Hz}) ; 6.97(\mathrm{~s}, 1 \mathrm{H}) ; 6.42(\mathrm{~d}, 1 \mathrm{H}, J=2.3 \mathrm{~Hz}) ; 5.71(\mathrm{~s}, 1 \mathrm{H})$; MS (EI. $70 \mathrm{eV}): m / z 312[\mathrm{M}+\mathrm{H}]^{+}$. 
TABLE 2: Cytotoxicity of the synthesized compounds against a panel of human cancer cell lines.

\begin{tabular}{|c|c|c|c|c|c|c|c|}
\hline \multirow{2}{*}{ Compound } & \multicolumn{7}{|c|}{$\mathrm{IC}_{50}(\mu \mathrm{M})$} \\
\hline & MCF-7 & MDA-MB 231 & U87G & OVCAR-8 & Mia PaCa-2 & HCT116 p53 & SKOV3 WT \\
\hline 1 & $>50$ & $>50$ & $>50$ & $\mathrm{nt}$ & $\mathrm{nt}$ & $\mathrm{nt}$ & $\mathrm{nt}$ \\
\hline 2 & $>50$ & $>50$ & $>50$ & $\mathrm{nt}$ & nt & nt & nt \\
\hline 3 & $>50$ & $>50$ & $>50$ & nt & nt & $\mathrm{nt}$ & nt \\
\hline 4 & $>50$ & $>50$ & $>50$ & nt & nt & nt & nt \\
\hline 5 & $>50$ & $42.4 \pm 0.6$ & $45.1 \pm 0.9$ & nt & nt & nt & nt \\
\hline 6 & $>50$ & $>50$ & $>50$ & nt & nt & nt & nt \\
\hline 7 & $>50$ & $>50$ & $>50$ & nt & nt & nt & nt \\
\hline 8 & $5.8 \pm 0.2$ & $8.7 \pm 0.1$ & $8.5 \pm 0.3$ & $3.4 \pm 0.4$ & $5.0 \pm 0.3$ & $11.1 \pm 0.5$ & $29.2 \pm 0.5$ \\
\hline 9 & $6.1 \pm 0.4$ & $9.7 \pm 0.3$ & $8.8 \pm 0.3$ & $3.8 \pm 0.6$ & $5.1 \pm 0.2$ & $13.3 \pm 0.6$ & $28.1 \pm 0.2$ \\
\hline 10 & $7.9 \pm 0.9$ & $9.7 \pm 0.3$ & $18.3 \pm 0.8$ & $6.9 \pm 0.9$ & $7.0 \pm 0.9$ & $19.3 \pm 0.6$ & $40.9 \pm 0.6$ \\
\hline
\end{tabular}

Each value represents the average of three independent experiments \pm SD.<smiles></smiles><smiles>[R]c1cc(C(=O)O)c(-n2cccc2)cc1[R4]</smiles>

Reagent and conditions.

(a) $\mathrm{MnO}_{2}$, toluene, reflux

SCHEMe 1

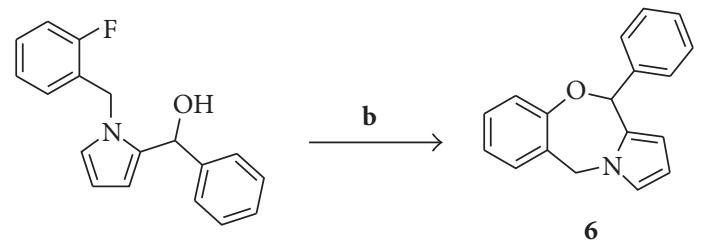

Reagent and conditions.

(b) $\mathrm{NaH}, \mathrm{DMF} / \mathrm{C}_{6} \mathrm{H}_{6}$

SCHEME 2

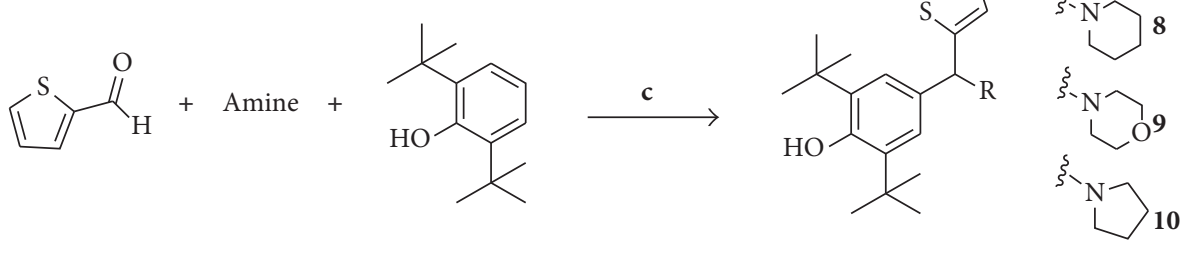

Reagent and conditions.

(c) Dry toluene, reflux 
2.1.7. General Procedure for the Synthesis of $N-\left(\left[1,1^{\prime}\right.\right.$-Biphenyl]4-methyl)-5-oxo-5H-benzo[d]pyrrolo[2,-b][1,3]oxazine-8-carboxamine (5). The starting 5-oxo-5H-benzo[d]pyrrolo[2,1$b][1,3]$ oxazine-8-carboxylic acid for the synthesis of compound 5 was obtained following the procedure mentioned above [25]. A solution of 5-oxo-5 $\mathrm{H}$-benzo[d]pyrrolo[2,1b][1,3] oxazine-8-carboxylic acid $(0.044 \mathrm{mmol}$; 1 eq. $)$ and $\mathrm{PCl}_{5}(0.053 \mathrm{mmol} ; 1.2 \mathrm{eq}$. $)$ in dry toluene $(0.1 \mathrm{~mL})$ was stirred at $\mathrm{rt}$, for $3 \mathrm{~h}$. To the obtained acyl chloride solution (0.04 mmol; 1 eq.), $\mathrm{Et}_{3} \mathrm{~N}$ (0.08 mmol; 2 eq.), and [1,1'biphenyl]-4-ylmethanamine $(0.06 \mathrm{mmol} ; 1.5$ eq. $)$ were added and the reaction mixture was kept at $\mathrm{rt}$ for $24 \mathrm{~h}$. Then, the solvent was evaporated under vacuum and the residue was solubilized in chloroform and washed with brine. The organic layer was dried over anhydrous $\mathrm{NaSO}_{4}$, filtered, and concentrated under vacuum. The pure compound was crystalized from chloroform.

2.1.8. N-([1,1'-Biphenyl]-4-methyl)-5-oxo-5H-benzo[d]pyrrolo[2,-b][1,3]oxazine-8-carboxamine (5). Yellow solid (8\% yield); mp: $165^{\circ} \mathrm{C} ;{ }^{1} \mathrm{HNMR}\left(\mathbf{C D C l}_{3}\right) \boldsymbol{\delta}: 7.70(\mathrm{~s}, 1 \mathrm{H}) ; 7.60-7.50$ (m, 3H); 7.50-7.30 (m, 9H); 7.15 (dd, $1 \mathrm{H}, J=0.8,2.6 \mathrm{~Hz}) ; 6.84$ $(\mathrm{dd}, 1 \mathrm{H}, J=0.8,3.7 \mathrm{~Hz}) ; 6.37(\mathrm{dd}, 1 \mathrm{H}, J=2.5,3.7 \mathrm{~Hz}) ; 4.71(\mathrm{~d}$, $2 \mathrm{H}, J=5.6 \mathrm{~Hz}$ ); MS (EI. $70 \mathrm{eV}): m / z 386[\mathrm{M}+\mathrm{H}]^{+}$.

2.1.9. General Procedure for the Synthesis of $11-P h e n y l-5 H, 11 \mathrm{H}-$ benzo[f]pyrrolo[2,1-c][1,4]oxazepine (6). The synthesis of the aforementioned compound was realized following the procedure described by Garofalo et al. [26] and by Effland and Davis [27].

2.1.10. 11-Phenyl-5H,11H-benzo[f]pyrrolo[2,1-c][1,4]oxazepine (6). Brown solid ( $41 \%$ yield); mp: $124-126^{\circ} \mathrm{C}$; ${ }^{1}$ HNMR (DMSO) $\delta: 7.60-7.45(\mathrm{~m}, 5 \mathrm{H}) ; 7.22(\mathrm{~s}, 1 \mathrm{H}) ; 6.97-6.83(\mathrm{~m}, 4 \mathrm{H})$; $6.80(\mathrm{~s}, 1 \mathrm{H}) ; 5.90-5.78(\mathrm{~m}, 1 \mathrm{H}) ; 5.45(\mathrm{~s}, 1 \mathrm{H}) ; 5.08-4.98(\mathrm{~d}, 1 \mathrm{H}$, $J=15.6 \mathrm{~Hz}) ;$ MS (EI. $70 \mathrm{eV}): m / z 262[\mathrm{M}+\mathrm{H}]^{+}$.

2.1.11. General Procedure for the Synthesis of 11-phenyl-5H,11Hbenzo[f]pyrrolo[2,1-c][1,4]thiazepine (7). The title compound was synthesized following the procedure described by Garofalo et al. [26].

2.1.12. 11-Phenyl-5H,11H-benzo[f]pyrrolo[2,1-c][1,4] thiazepine (7). Beige solid ( $46 \%$ yield); mp: $126-128^{\circ} \mathrm{C} ;{ }^{1}$ HNMR: known compound [26].

2.1.13. General Procedure for the Synthesis of 4-Methyl Substituted 2,6-di-tert-butylphenol Derivatives (8-10). A stirred solution of thiophene-2-carbaldehyde (1.05 eq.) and secondary heterocyclic amine (2.31 eq.) in dry toluene was refluxed $\left(110^{\circ} \mathrm{C}\right)$, under $\mathrm{N}_{2}$ atmosphere, overnight. Then, the reaction mixture was cooled down to $90^{\circ} \mathrm{C}$ and a solution of 2,6-di-tert-butylphenol in dry toluene was added, drop by drop. The reaction mixture was refluxed again, under $\mathrm{N}_{2}$ atmosphere, overnight. The solvent was evaporated under vacuum; methanol was added to the reaction residue and was stirred and heated at $60^{\circ} \mathrm{C}$, for 30 minutes. The obtained precipitate was collected by filtration and purified by crystallization from methanol or by chromatographic column on silica gel (n-hexane/ethyl acetate, different ratios, as eluent).

2.1.14. 2,6-Di-tert-butyl-4-(piperidin-1-yl(thiophen-2-yl)meth$y$ l)phenol (8). Yellow solid (33\% yield); $\mathrm{mp}: 133-34^{\circ} \mathrm{C}$; ${ }^{1}$ HNMR (DMSO) $\boldsymbol{\delta}: 7.39-7.36(\mathrm{~m}, 1 \mathrm{H}) ; 7.14(\mathrm{~s}, 2 \mathrm{H}) ; 6.92-6.87$ (m, 2H); 6.85 (bs, 1H); 4.55 (s, 1H); $2.25(\mathrm{~s}, 4 \mathrm{H}) ; 1.52$ (s, 6H); $1.35(\mathrm{~s}, 18 \mathrm{H}) ;{ }^{13} \mathrm{CNMR}\left(\mathbf{C D C l}_{3}\right) \boldsymbol{\delta}: 24.66,26.26(\mathrm{x} 2 \mathrm{C}), 30.28$ (x6C), 34.34 (x2C), 52.26 (x2C), 71.31, 124.40, 124.93, 125.06 (x2C), 125.95, 131.40, 135.15, 148.50, 148.52, 152.57. HRMS: $m / z$ $384[\mathrm{M}-\mathrm{H}]^{-}, 301[\mathrm{M} \text { - piperidinyl }]^{-}$.

2.1.15. 2,6-Di-tert-butyl-4-(morpholino(thiophen-2-yl)meth$y$ l)phenol (9). Reddish orange oil (46\% yield); ${ }^{1}$ HNMR (DMSO) $\delta$ : $7.99(\mathrm{~d}, 1 \mathrm{H}, J=3.0 \mathrm{~Hz}) ; 7.85(\mathrm{~s}, 1 \mathrm{H}) ; 7.68(\mathrm{~s}, 1 \mathrm{H})$; $7.58(\mathrm{~d}, 1 \mathrm{H}, J=3.0 \mathrm{~Hz}) ; 7.28-7.24(\mathrm{~m}, 1 \mathrm{H}) ; 7.18-7.15(\mathrm{~m}, 1 \mathrm{H})$; $6.87(\mathrm{~s}, 1 \mathrm{H}) ; 4.01-3.98(\mathrm{~m}, 4 \mathrm{H}) ; 2.10-1.98(\mathrm{~m}, 4 \mathrm{H}) ; 1.30(\mathrm{~s}$, 9H); 1.24 (s, 9H); ${ }^{13}$ CNMR $\left(\mathbf{C D C l}_{3}\right) \boldsymbol{\delta}: 31.60$ (x6C), 34.72 (x2C), 52.13 (x2C), 66.99 (x2C), 71.65, 125.01 (x2C), 125.51, $126.81,127.04,127.96,136.13,148.50,148.52,152.57$. HRMS: $\mathrm{m} / \mathrm{z} 301$ [M - morpholino] $^{-}$.

2.1.16. 2,6-Di-tert-butyl-4-(pyrrolidin-1-yl(thiophen-2-yl)meth$y$ l)phenol (10). Brown oil (46\% yield); ${ }^{1}$ HNMR (DMSO) $\boldsymbol{\delta}$ : $8.0(\mathrm{~d}, 1 \mathrm{H}, J=3.0 \mathrm{~Hz}) ; 7.84(\mathrm{~s}, 1 \mathrm{H}) ; 7.67(\mathrm{~s}, 1 \mathrm{H}) ; 7.57(\mathrm{~d}, 1 \mathrm{H} J=$ $3.0 \mathrm{~Hz}) ; 7.29-7.24$ (m, 1H); 7.20-7.16 (m, 1H); 7.13 (s, 1H); 1.48 (s, 8H); 1.30 (s, 9H); 1.24 (s, 9H); HRMS: $m / z 372[\mathrm{M}+\mathrm{H}]^{+}$.

\subsection{Biology}

2.2.1. Cell Culture. All used tumor cell lines (MCF-7, MDAMB 231, U87G, OVCAR-8, Mia PaCa-2, HCT116 $553^{+/+}$, and SKOV3 WT) were grown at $37^{\circ} \mathrm{C}$ in a humidified incubator with 5\% $\mathrm{CO}_{2}$, in RPMI-1640 medium supplemented with $10 \%$ fetal bovine serum (FBS). The culture medium was changed twice a week.

2.2.2. Treatment with Synthesized Compounds and MTT Colorimetric Assay. Cells were seeded in $180 \mu \mathrm{L}$ medium in 96-well plates and incubated at $37^{\circ} \mathrm{C}$. After overnight attachment, cells were treated with the compounds (final concentration from $30 \mu \mathrm{M}$ to $0.12 \mu \mathrm{M}$, in duplicate). DMSO was used as negative control. Plates were incubated in the presence of compounds for $72 \mathrm{~h}$ and then cytotoxicity was measured with colorimetric assay, based on the use of MTT (3-(4,5-dimethylthiazol-2-yl)-2,5-diphenyltetrazolium bromide). $20 \mu \mathrm{L}$ of MTT solution in DPBS (Dulbecco's phosphate-buffered saline) $(3 \mathrm{mg} / \mathrm{mL})$ was added and plates were incubated for 3-4h. Mitochondrial reductase enzymes in viable cells reduce the yellow tetrazolium MTT in its formazan, which has a purple color when dissolved in DMSO. Media were finally replaced with $125 \mu \mathrm{L}$ of DMSO and cell viability was determined by measuring absorbance on a multiwell scanning spectrophotometer, using a wavelength of $570 \mathrm{~nm}$. The $\mathrm{IC}_{50}$ (half-maximum inhibitory concentration) values were determined using GraphPad Prism and expressed 
as average of three independent experiments \pm standard deviation (SD) value.

2.2.3. Colony Formation Assay. Cells were seeded in $180 \mu \mathrm{L}$ medium in 96-well plates and allowed to attach overnight at $37^{\circ} \mathrm{C}$. Then, cells were treated with the compounds (final concentrations $10 \mu \mathrm{M}, 5 \mu \mathrm{M}$, and $1 \mu \mathrm{M}$, in duplicate). DMSO was used as negative control. After $24 \mathrm{~h}$ treatment, compoundcontaining medium was carefully removed and replaced with $200 \mu \mathrm{L}$ of fresh medium supplemented with $10 \%$ FBS. Cells were kept in culture at $37^{\circ} \mathrm{C}$ until visible colonies were formed in control wells. Then, medium was removed and colonies were stained with $50 \mu \mathrm{L}$ of $0.5 \%$ crystal violet solution for $30 \mathrm{~min}$ at rt. Finally, colonies were washed 3 times with $100 \mu \mathrm{L}$ of water to remove excessive stain and allowed to dry overnight under hood. Colonies were imaged with Odyssey Imaging System (LI-COR Biosciences, Lincoln, NE).

2.2.4. Scratch Wound Healing Assay. Cells were seeded in 96well plates, at a high density to have $70-80 \%$ confluency after overnight incubation at $37^{\circ} \mathrm{C}$, and then starved for $24 \mathrm{~h}$. Using $200 \mu \mathrm{L}$ tip, every well was gently and slowly scratched and washed twice with DPBS. Fresh medium, supplemented with $5 \%$ FBS and containing compounds (final concentrations $10 \mu \mathrm{M}$ and $1 \mu \mathrm{M}$ ), was added and cells were grown at $37^{\circ} \mathrm{C}$, until the wound in control wells was closed. Finally, medium was removed and cells were stained with $50 \mu \mathrm{L}$ of $0.5 \%$ crystal violet solution for $30 \mathrm{~min}$ at rt. Finally, cells were washed 3 times with $100 \mu \mathrm{L}$ of water to remove excessive stain and allowed to dry overnight under hood. Wells were imaged with Odyssey Imaging System (LI-COR Biosciences, Lincoln, NE).

2.2.5. Measurement of PDI Reductase Activity. Reductase activity was assayed by measuring the PDI-catalyzed reduction of insulin in the presence of compounds (final concentrations from $30 \mu \mathrm{M}$ to $0.33 \mu \mathrm{M}$, in duplicate) in a $100 \mu \mathrm{L}$ reaction volume containing $0.5 \mathrm{mM}$ DTT, $100 \mathrm{mM}$ sodium phosphate buffer, $\mathrm{pH}$ 7.0, 0.5 mM DTT, 2 mM EDTA, $0.13 \mathrm{mM}$ bovine insulin (Sigma), and $1.3 \mu \mathrm{M}$ purified human PDI. Then, the aggregation of reduced insulin chains was measured spectrophotometrically at $650 \mathrm{~nm}$. The $\mathrm{IC}_{50}$ values were determined using GraphPad Prism and expressed as average of three independent experiments \pm standard deviation value.

\section{Results and Discussion}

Using an insulin-based turbidimetric assay [16], we screened a small library of various chemical scaffolds to identify small molecules suitable to inhibit PDI. The assay identified the lactone as an inhibitory compound of PDI. Heterocycles are widely studied because of their well-known biological activities, among these indole and pyrrole frames. Due to their attractive importance, we designed and synthesized some indole lactones, variously substituted with both electron-donor and attractor groups. We also synthesized pyrrole lactones, bearing different substituents, such as the amide moiety. Finally, we wanted to enlarge the central six-membered ring of the lactone structure into a sevenmembered heterocycle, containing either oxygen or sulfur atom and bearing an appended phenyl ring. All the chemical modifications were investigated with the aim of better understanding whether the new synthesized molecules could improve the potency of the lead compound, against PDI.

Recent studies have suggested that PDI can bind small molecules containing, for example, a phenolic structure, which includes endogenous hormones like estrogen. In particular, it has been demonstrated that estradiol fits into a hydrophobic pocket placed between the $\mathbf{b}$ and the $\mathbf{b}^{\prime}$ domains of PDI and its hydroxyl group on C3 interacts with the histidine residue present in position 256, through formation of an H-bond (Figure 4) [6]. A class of PACMAs has exhibited cytotoxic effect in a panel of human cancer cell lines, especially against the resistant ovarian cancer cell line NCI/ADR-RES [28]. A series of PACMAs, electron-deficient compounds, were identified as potent PDI inhibitors, able to react irreversibly with the thiol groups of cysteines in the catalytically active site of PDI, forming covalent adducts. In particular, PACMA 31 showed an anticancer activity in human ovarian cancer, both in vitro and in vivo. It has been suggested that the electrophilic alkyne group of PACMA 31 is essential for its cytotoxicity [24].

Based on the structure of $E_{2}$ and PACMA 31, we designed a new class of 4-methyl substituted 2,6-di-tert-butylphenol derivatives, simplifying the structure of the known modulators. The phenolic frame, the hydroxyl group, and the appended thiophene ring were kept in the same position of $\mathrm{E}_{2}$ and PACMA 31, substituting the propionyl group with a tertbutyl and the amide moiety with a cyclic amine (Figure 5).

PDI catalyzes the reduction of insulin in the presence of dithiothreitol (DTT); the reduced insulin chains aggregate and turbidimetry is monitored using a spectrophotometer. Reductase activity of PDI was, then, assayed by measuring the reduction of insulin, in the presence of compounds. Firstly, all synthesized compounds were screened in the insulin turbidimetry assay, at a single concentration $(100 \mu \mathrm{M})$. As shown in Table 1, three lactone derivatives 3-5 and all 4-methyl substituted 2,6-di-tert-butylphenol derivatives 8-10 showed the best inhibition of PDI reductase activity (inhibition > $80 \%)$.

Dose-response curves and $\mathrm{IC}_{50}$ values were calculated for the most potent compounds. Compounds 8-10 inhibited PDI in a dose-dependent manner; in particular, piperidine and morpholine derivatives showed an $\mathrm{IC}_{50}$ lower than $2 \mu \mathrm{M}$ (Figure 6).

These results suggest that although lactone frame could moderately inhibit the reductase activity of PDI, 4-methyl substituted 2,6-di-tert-butylphenol structure is better suited as potential PDI inhibitor.

Increased levels of PDI have been found in a variety of human cancer cell lines, including ovarian ones [16]. Increasing evidence suggests that PDI supports the survival and proliferation of several cancer types. In particular, it has been showed that PDI activity is essential for human ovarian cancer cells [24]. To demonstrate the PDI inhibitory activity of the synthesized compounds and verify a correlation between the inhibition of both PDI and cancer cell growth, we 


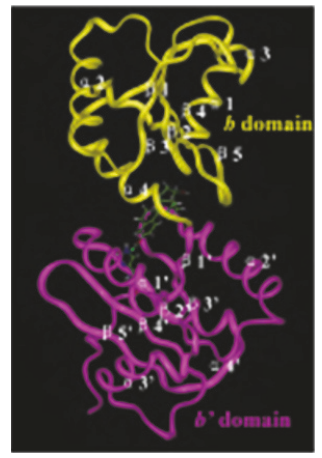

(a)

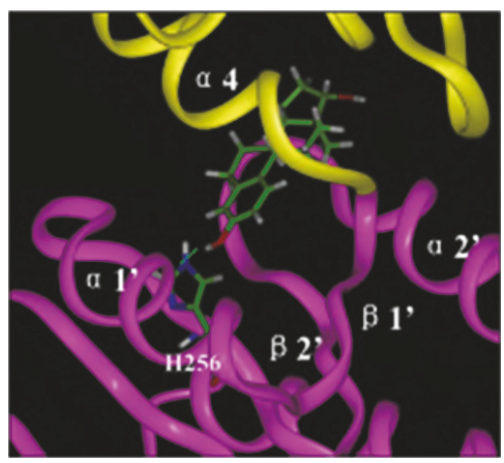

(b)

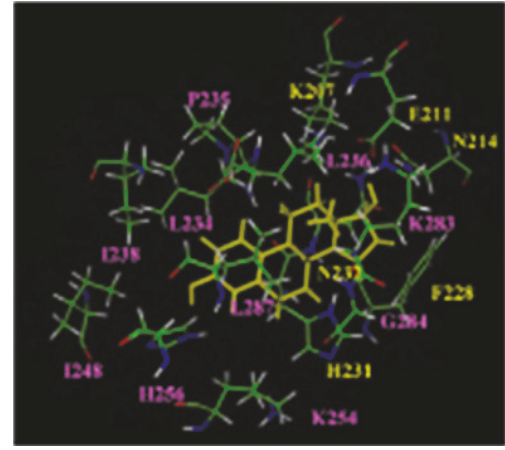

(c)

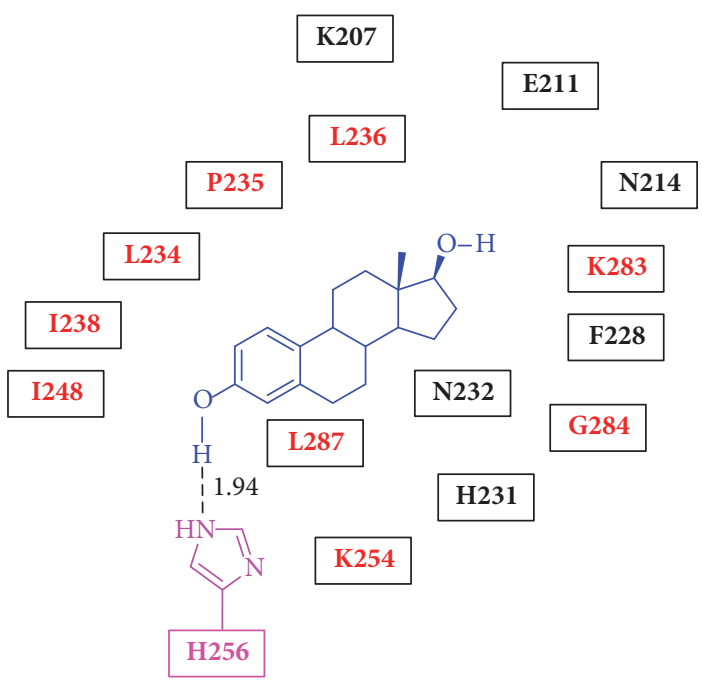

(d)

FIgURE 4: Docking analysis of the binding interaction of $\mathrm{E}_{2}$ inside human PDI b-b' fragment (Figure by Fu et al. [6]).

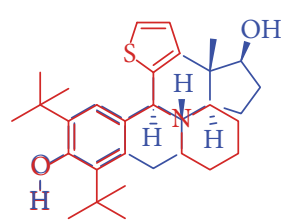

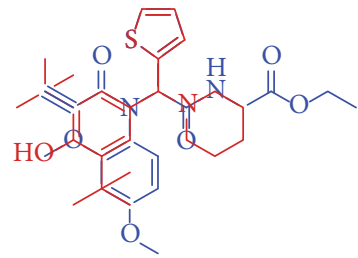

FIGURE 5: Superimposition of new 4-methyl substituted 2,6-di-tertbutylphenol derivatives and known modulators.

determined the cytotoxicity of all derivatives against a panel of human cancer cell lines (Table 2).

We chose seven different human cancer cell lines, which include breast, ovarian, brain, colorectal, and pancreatic cancer and investigated a selectivity of synthesized compounds against a specific cancer type. The synthesized heterocyclic compounds did not show a potent antiproliferative effect in all tested cell lines; only compound $\mathbf{5}$ exhibited a moderate cytotoxicity against breast and brain cancer cells. On the other hand, the new derivatives $\mathbf{8 - 1 0}$ were cytotoxic in all the chosen cell lines.
It is important to note that they showed the best antiproliferative activity in the human ovarian cancer cells with $\mathrm{IC}_{50}$ values lower than $10 \mu \mathrm{M}$. Additionally, the same compounds showed the capability to inhibit the formation of colonies and the migration of human ovarian cancer cells (Figure 7).

These results confirm PDI as preferred target of the new 4-methyl substituted 2,6-di-tert-butylphenol derivatives. Although they could bind PDI in a similar way of $E_{2}$, by forming an $\mathrm{H}$-bond with a specific residue in the protein structure, additional experiments are ongoing to verify the site of binding and the mode of action of 4-methyl substituted 2,6-di-tert-butylphenol derivatives.

\section{Conclusions}

Recently, PDI has been considered an attracting drug target especially for cancer therapy. With this purpose, we designed and synthesized a diversified small library of compounds and evaluated their inhibitory effects against the reductase activity of PDI. The 4-methyl substituted 2,6-di-tert-butylphenol derivatives, with an aliphatic cyclic amine, exhibited the best inhibition with $\mathrm{IC}_{50}$ values lower than $2 \mu \mathrm{M}$ (8 and $\left.\mathbf{9}\right)$ and $5 \mu \mathrm{M}$ (10). The possible involvement of PDI inhibition 


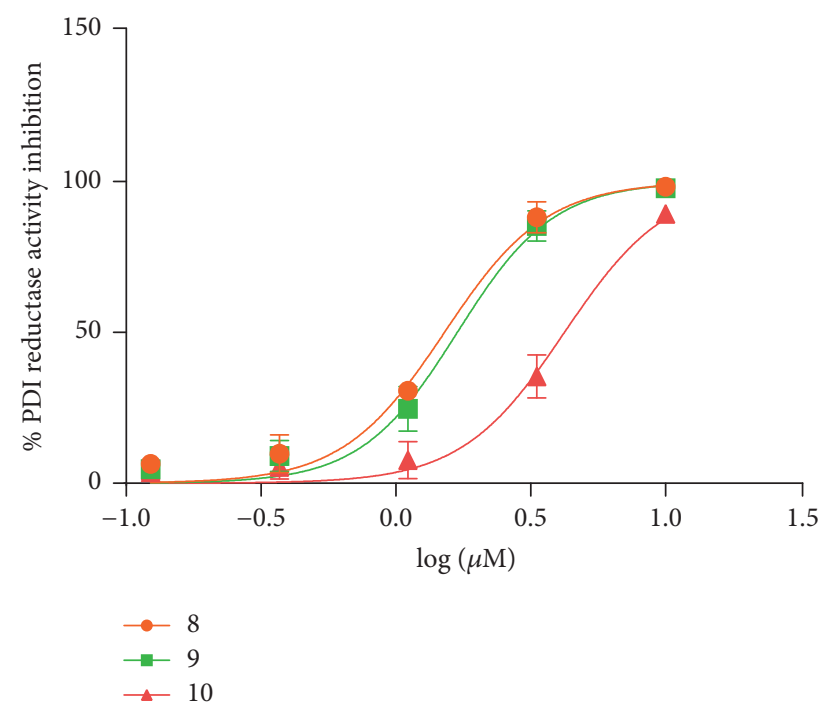

FIGURE 6: Dose-response curves of the most potent compounds.

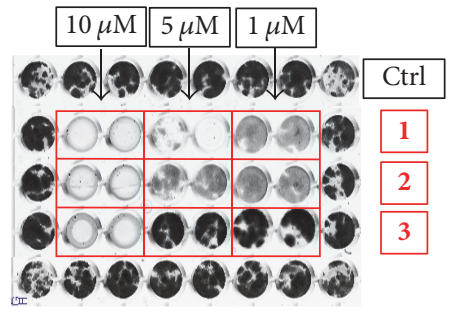

(a)

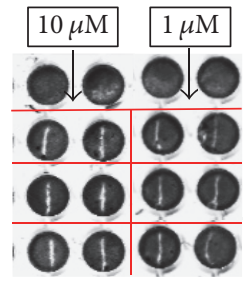

(b)
FIGURE 7: Inhibition of colony formation (a) and migration (b) of OVAR-8 cells.

in the mechanism of action of the mentioned compounds was confirmed with the antiproliferative activity in vitro, in particular against human ovarian cancer cell line. These results encourage further investigation about the binding and mode of action of 4-methyl substituted 2,6-di-tertbutylphenol derivatives and a biological evaluation in vivo, as anticancer PDI inhibitors.

\section{Additional Points}

Supplementary Data. Supplementary data associated with this article can be found at https://doi.org/10.1155/2017/2370359.

\section{Conflicts of Interest}

The authors declare no conflicts of interest regarding the publication of this paper.

\section{Acknowledgments}

The authors thank Professor Nouri Neamati at the Department of Medicinal Chemistry, College of Pharmacy, and Translational Oncology Program, University of Michigan, North Campus Research Complex, 2800 Plymouth Road,
Building 520, Ann Arbor, MI 48109, USA, for allowing them to perform the biological assays in his facilities.

\section{References}

[1] G. Kozlov, P. Määttänen, D. Y. Thomas, and K. Gehring, "A structural overview of the PDI family of proteins," FEBS Journal, vol. 277, no. 19, pp. 3924-3936, 2010.

[2] H. A. Khan and B. Mutus, "Protein disulfide isomerase a multifunctional protein with multiple physiological roles," Frontiers in Chemistry, vol. 2, no. 70, pp. 1-9, 2014.

[3] S. Parakh and J. D. Atkin, "Novel roles for protein disulphide isomerase in disease states: a double edged sword?" Frontiers in Cell and Developmental Biology, vol. 3, no. 30, pp. 1-11, 2015.

[4] G. Tian, F.-X. Kober, U. Lewandrowski, A. Sickmann, W. J. Lennarz, and H. Schindelin, "The catalytic activity of protein-disulfide isomerase requires a conformationally flexible molecule," Journal of Biological Chemistry, vol. 283, no. 48, pp. 33630-33640, 2008.

[5] X. Fu, P. Wang, and B. T. Zhu, "Protein disulfide isomerase is a multifunctional regulator of estrogenic status in target cells," Journal of Steroid Biochemisty \& Molecular Biology, vol. 112, pp. 127-137, 2008.

[6] X.-M. Fu, P. Wang, and B. T. Zhu, "Characterization of the estradiol-binding site structure of human protein disulfide isomerase (PDI)," PLoS ONE, vol. 6, 1, no. 11, article e27185, p. $10,2011$.

[7] F. Hatahet and L. W. Ruddock, "Protein disulfide isomerase: a critical evaluation of its function in disulfide bond formation," Antioxidants and Redox Signaling, vol. 11, no. 11, pp. 2807-2850, 2009.

[8] O. Serve, Y. Kamiya, and K. Kato, "Redox-Dependent Chaperoning, following PDI Footsteps," in Protein Folding, E. C. Walters, Ed., pp. 489-500, NOVA Science Publishers, New York, NY, USA, 2011.

[9] A. K. Wallis and R. B. Freedman, "Assisting oxidative protein folding: How do protein disulphide-isomerases couple conformational and chemical processes in protein folding?" Topics in Current Chemistry, vol. 328, pp. 1-34, 2013.

[10] P. Klappa, H. C. Hawkins, and R. B. Freedman, "Interactions between protein disulphide isomerase and peptides," European Journal of Biochemistry, vol. 248, no. 1, pp. 37-42, 1997.

[11] K. R. Hasan, S. M. Khursheed, and P. Salahuddin, "Protein disulfide isomerase: structure, mechanism of oxidative protein folding and multiple functional roles," Journal of Biochemistry and Molecular Biology Research, vol. 2, no. 3, pp. 173-179, 2016.

[12] H. F. Gilbert, "Protein disulfide isomerase and assisted protein folding," Journal of Biological Chemistry, vol. 272, no. 47, pp. 29399-29402, 1997.

[13] M. Molinari, C. Galli, V. Piccaluga, M. Pieren, and P. Paganetti, "Sequential assistance of molecular chaperones and transient formation of covalent complexes during protein degradation from the ER," Journal of Cell Biology, vol. 158, no. 2, pp. 247-257, 2002.

[14] S.-O. Lee, K. Cho, S. Cho, I. Kim, C. Oh, and K. Ahn, "Protein disulphide isomerase is required for signal peptide peptidasemediated protein degradation," EMBO Journal, vol. 29, no. 2, pp. 363-375, 2010.

[15] C. Turano, S. Coppari, F. Altieri, and A. Ferraro, "Proteins of the PDI family: Unpredicted non-ER locations and functions," Journal of Cellular Physiology, vol. 193, no. 2, pp. 154-163, 2002. 
[16] S. Xu, S. Sankar, and N. Neamati, "Protein disulfide isomerase: a promising target for cancer therapy," Drug Discovery Today, vol. 19, no. 3, pp. 222-240, 2014.

[17] P. Thongwatchara, W. Promwikorn, C. Srisomsap, D. Chokchaichamnankit, P. Boonyaphiphat, and P. Thongsuksai, "Differential protein expression in primary breast cancer and matched axillary node metastasis," Oncology Reports, vol. 26, no. 1, pp. 185-191, 2011.

[18] T. Hashida, Y. Kotake, and S. Ohta, "Protein disulfide isomerase knockdown-induced cell death is cell-line-dependent and involves apoptosis in MCF-7 cells," Journal of Toxicological Sciences, vol. 36, no. 1, pp. 1-7, 2011.

[19] D. Goplen, J. Wang, P. Ø. Enger et al., "Protein disulfide isomerase expression is related to the invasive properties of malignant glioma," Cancer Research, vol. 66, no. 20, pp. 98959902, 2006.

[20] P. E. Lovat, M. Corazzari, J. L. Armstrong et al., "Increasing melanoma cell death using inhibitors of protein disulfide isomerases to abrogate survival responses to endoplasmic reticulum stress," Cancer Research, vol. 68, no. 13, pp. 5363-5369, 2008.

[21] B. G. Hoffstrom, A. Kaplan, R. Letso et al., "Inhibitors of protein disulfide isomerase suppress apoptosis induced by misfolded proteins," Nature Chemical Biology, vol. 6, no. 12, pp. 900-906, 2010.

[22] M. Gao, Q. Yang, M. Wang, K. D. Miller, G. W. Sledge, and Q.-H. Zheng, "Synthesis of radiolabeled protein disulfide isomerase (PDI) inhibitors as new potential PET agents for imaging of the enzyme PDI in neurological disorders and cancer," Applied Radiation and Isotopes, vol. 74, pp. 61-69, 2013.

[23] R. Jasuja, F. H. Passam, D. R. Kennedy et al., "Protein disulfide isomerase inhibitors constitute a new class of antithrombotic agents," The Journal of Clinical Investigation, vol. 122, no. 6, pp. 2104-2113, 2012.

[24] S. Xu, A. N. Butkevich, R. Yamada et al., "Discovery of an orally active small-molecule irreversible inhibitor of protein disulfide isomerase for ovarian cancer treatment," Proceedings of the National Academy of Sciences of the United States of America, vol. 109, no. 40, pp. 16348-16353, 2012.

[25] F. Grande, A. Brizzi, A. Garofalo, and F. Aiello, "Active manganese dioxide promoted cyclization of ortho- $(1 \mathrm{H}-$ pyrrol1-yl)aryl and heteroaryl carboxylic acids to $5 \mathrm{H}$-pyrrolo[1,2a][3,1]benzoxazin-5-one derivatives," Tetrahedron, vol. 69, no. 47, pp. 9951-9956, 2013.

[26] A. Garofalo, G. Campiani, V. Nacci, and I. Fiorini, "Polycondensed heterocycles. VIII. Synthesis of 11 -aryl-5H,11Hpyrrolo[2,1-c][1,4]benzothiazepines by pummerer rearrangement-cyclization reaction," Heterocycles, vol. 34 , no. 1, pp. 5160, 1992.

[27] R. C. Effland and L. Davis, "Synthesis of pyrrolo[2,1-c][1,4]benzoxazepines. 1. A novel heterocyclic ring system," Journal of Heterocyclic Chemistry, vol. 22, no. 4, pp. 1071-1075, 1985.

[28] R. Yamada, X. Cao, A. N. Butkevich et al., "Discovery and preclinical evaluation of a novel class of cytotoxic propynoic acid carbamoyl methyl amides (PACMAs)," Journal of Medicinal Chemistry, vol. 54, no. 8, pp. 2902-2914, 2011. 

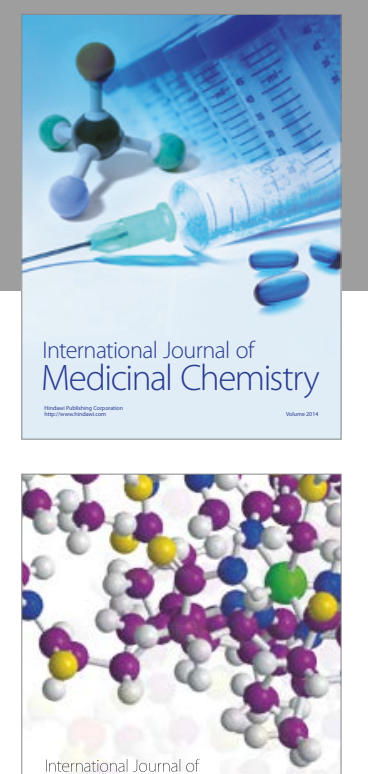

Carbohydrate Chemistry

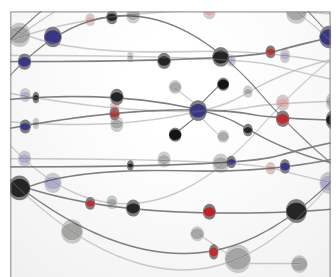

The Scientific World Journal
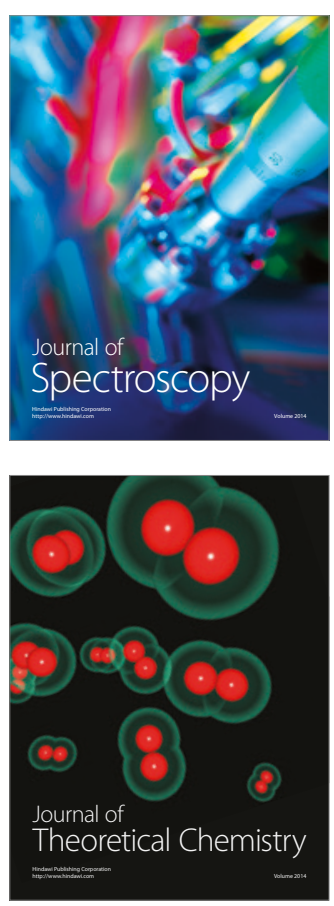
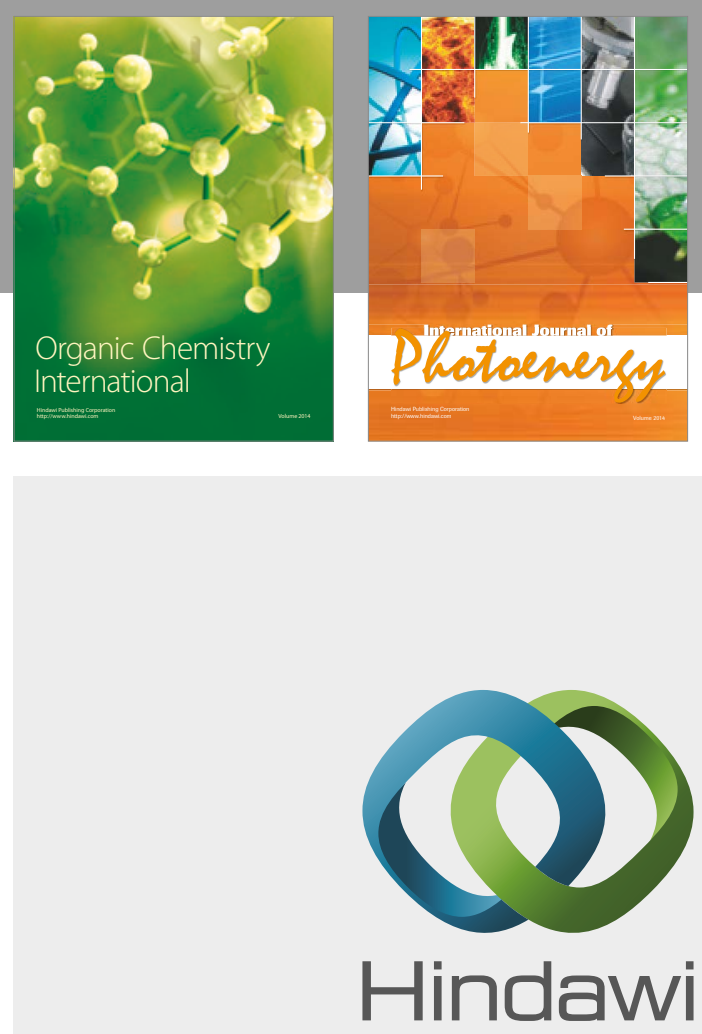

Submit your manuscripts at

https://www.hindawi.com

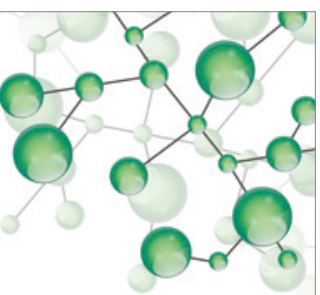

International Journal of

Inorganic Chemistry

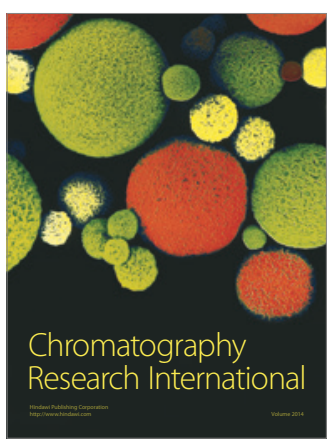

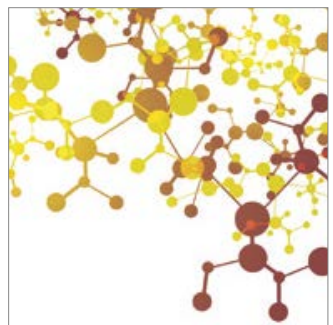

Applied Chemistry
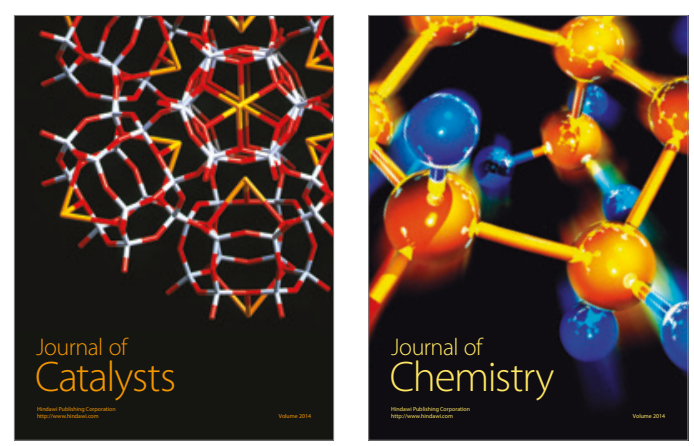
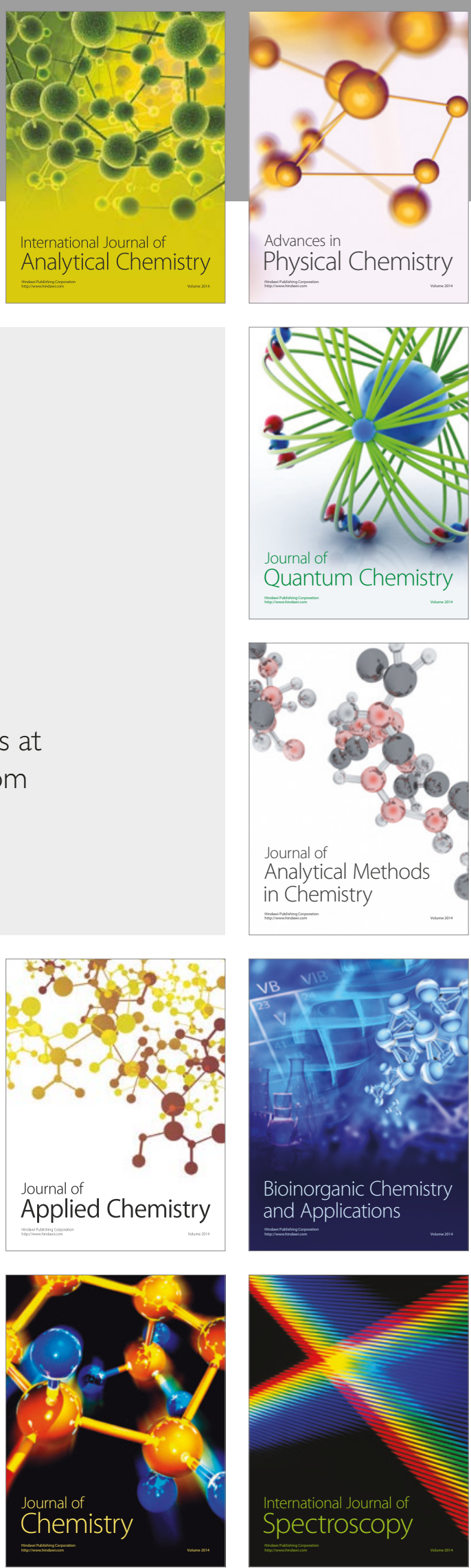